\title{
Regression Analysis of Artificial Hail Suppression Effect in Akesu Prefecture of Southern Xinjiang
}

\author{
Zheng Bohua, Li Bin, Shi Lianmei, Zhu Sihua \\ Weather Modification Office of Xinjiang Uygur Autonomous Region, Urumqi, China \\ Email address: \\ 115125991@qq.com (Zheng Bohua),btlibin@126.com (Li Bin)
}

To cite this article:

Zheng Bohua, Li Bin, Shi Lianmei, Zhu Sihua. Regression Analysis of Artificial Hail Suppression Effect in Akesu Prefecture of Southern Xinjiang. American Journal of Environmental Science and Engineering. Vol. 2, No. 3, 2018, pp. 43-48. doi: 10.11648/j.ajese.20180203.12

Received: October 19, 2018; Accepted: November 27, 2018; Published: December DD, 2018

\begin{abstract}
To further evaluate the differences of annual hailstorm areas before and after the scientifically carrying out artificial hail suppression period in Akesu in the hope of analyzing the effect. In this paper, the method of the regression test of areas was applied, the differences of annual hailstorm areas before and after 18a of the scientifically carrying out artificial hail suppression period in Akesu were analyzed with annual hailstorm areas data from 1978 - 2013 in Akesu and Kashi with 1996 as the year of artificial hail suppression. The results showed that the average annual hail area was reduced $23802 \mathrm{hm}^{2}$, and the relative loss rate was $54.5 \%$ after the operation of scientifically artificial hail suppression in Akesu. Combined with the agricultural economic data, the average annual reduction of hail disaster loss was 444,170,000 RMB, annual input and output ratio nearly was 1:10. The statistical significant level highly reached $\alpha=0.01$. Therefore, through scientifically carrying out artificial hail suppression operations, it is obvious that hail disaster losses reduced and the social and economic benefits are great in Akesu.
\end{abstract}

Keywords: Artificial Hail Suppression, Regression Test of Areas, Performance and Effect Evaluation

\section{Introduction}

\subsection{Significance}

Xinjiang is one of the most frequent occurrences of hail disasters in northwestern China [1]. The Akesu region and the Kashgar region are located in the southern and western margins of the middle Tianshan Mountains, and from the northern margin to the northwestern margin of the Tarim Basin. The summer is hot and humid, with little rainfall, large evaporation, and abundant light and heat resources. There are many underlying surface distributions in the two regions, such as mountains, plains, deserts, oases, rivers, reservoirs, etc., and the types of landforms are complex. The main features of the terrain are: mountains in the north, deserts in the south, plains, oases, rivers, reservoirs, etc. in the middle. The surface conditions are uneven, undulating, and it is easy to form hail weather. The Yarkant River Basin, the Sui River Basin and the Akesu River Basin in the region are three of the nine major hail occurrence areas in Xinjiang [2]. The annual economic losses caused by natural disasters such as hail and floods amount to several hundred million yuan, which has seriously affected the economic and social development of southern Xinjiang. With the global warming in recent years, the strong hail weather in the Akesu and Kashgar areas is increasing [2-3]. Since 1994, the Akesu area has used the World Bank loan project to build the first C-band Doppler weather radar in Xinjiang in Shaya County, and officially put into operation in 1996. Subsequently, 148 sets of new artificial weather-influencing rocket launching systems, 1 new-generation weather radar, and $1 \mathrm{X}$-band dual-polarized weather radar were introduced, and an advanced artificial flood control system was established. In the Kashgar area, it was only in the past two years that the artificial flood control work was carried out scientifically and systematically.

\subsection{Predecessor Research}

In recent years, many scholars in China have analyzed the climatic characteristics, temporal and spatial distribution, and disaster situation of hail weather [4-6], forecasting and early warning methods [7-11] and hail formation mechanism, anti-cluster catalysis principle and flood control and 
mitigation effects [12-14] Research has been carried out in other areas. Because Xinjiang is a flood-prone area; in the face of serious disasters that threaten the economic development of agriculture and animal husbandry in Xinjiang, Xinjiang meteorologists have carried out targeted research work, Wang Qiuxiang et al [15] systematically analyzed the distribution characteristics of disaster losses in Xinjiang. It is pointed out that the Akesu area is the most serious area for disaster relief in Xinjiang, and it is necessary to carry out key defenses; Chen Hongwu [16], Wang Xu, Ma Wei [17-18] studied the time of occurrence of Xinjiang hail, and statistically analyzed the systematic hail weather. The circulation situation; Yang Lianmei et al [19] reached a meaningful conclusion in the climate characteristics and defense countermeasures of Xinjiang hail; Li Lihua et al [20] completed the risk zoning of five risk zones in the Akesu region by means of ArcGIS. These research results basically reveal the occurrence and changing characteristics of the hail weather in Xinjiang. However, based on the scientific complexity of the formation and evolution of the strong convective weather system and the technical complexity of the artificial catalytic operation, it is very difficult to test the effect of artificial flood control.

\subsection{Entry point of this Study}

Li Bin et al [21] have used some statistical methods to evaluate the effect of artificial flood control in the Akesu area. However, in order to further evaluate the effectiveness of artificial anti-mite operation, it is necessary to use different statistical evaluation methods, especially to evaluate more efficient and accurate regional regression analysis. This paper is based on the information on the area of disaster relief in the Akesu area in 1996 before and after the artificial flood control operation (these are called the historical period and the operation period), and the information on the disaster area in Kashgar from 1978 to 2013, targeting the Akesu area. District, Kashgar area as a comparison area, using regional regression analysis to determine the reduction rate of disaster relief area in Akesu area, combined with the agricultural economic data of the area, the input-output ratio of artificial flood control operation. In order to make use of different statistical evaluation methods, it provides a technical method and scientific basis for scientifically quantitative evaluation of artificial flood control operations, and further improves the level of artificial flood control scientific operations.

\section{Materials and Methods}

\subsection{Materials}

The area of disaster relief in Akesu and Kashgar from 1978 to 2013 came from the climate center of the Meteorological Bureau of Xinjiang Uygur Autonomous Region. The corresponding cultivated land area and agricultural output value data are derived from the Xinjiang Statistical Yearbook. The above data are the sum of the corresponding annual data of 8 counties and 1 city in Akesu area and 11 counties and 1 city in Kashgar, and carry out rigorous verification and verification, in which individual abnormalities, repeated data are analyzed, consulted, and rejected after review.

The area of the text is the area of cultivated land, and the unused planted area is used as the benchmark. The reason is that considering the factors such as frost in the spring and gale disasters, some cultivated land that has been planted will be re-broadcast or re-broadcast, and the planting area will increase. The output value is based on the agricultural output value after the removal of forestry and animal husbandry output value. It is considered that the hail disaster mainly causes loss to crop crops.

\subsection{Methods}

The regional regression analysis is to establish a statistical regression equation corresponding to the statistical variables of the historical time series of the target area and the comparison area based on the historical data by means of one or more comparison areas. Assuming that the statistical variables of the two regions in the operation period satisfy the above regression relationship, the statistical regression equation is used to derive the natural value of the statistical variable in the target area of the operation period from the statistical variable value of the comparison period in the operation period, which is also called the natural statistical variable of the target area in the operation period. The expected value is compared with the actual statistical variable value in the target area of the operation period, and the evaluation result of the statistical variable of the target period of the operation period can be obtained.

Information on the annual disaster area (in ha) in the Kashgar area as a comparison area and the Akesu area as a target area. The annual disaster area of the contrast area is $x_{i}{ }^{\prime}$, the annual disaster area of the target area is $y_{i}{ }^{\prime}$, the area of the annual disaster relief area in the comparison area is $x_{i}$, and the area of the annual disaster area is $y_{i}, x_{i}{ }^{\prime}=x_{i}{ }^{4}, y_{i}{ }^{\prime}=y_{i}{ }^{4}$, the relevant calculation results are as follows:

Table 1. Results of regression statistical analysis and calculation with the annual hail damaged areas in object-comparative areas.

\begin{tabular}{|c|c|c|c|c|c|c|c|}
\hline Years & $x_{i}^{\prime}$ & $y_{i}^{\prime}$ & $x_{i}$ & $y_{i}$ & $\left(x_{i}-\bar{x}\right)^{2}$ & $\left(y_{i}-\bar{y}\right)^{2}$ & $\left(x_{i}-\bar{x}\right)\left(y_{i}-\bar{y}\right)$ \\
\hline \multicolumn{8}{|c|}{ (Historical period) } \\
\hline 1978 & 0 & 3004 & 0.0000 & 7.4033 & 56.6338 & 36.0315 & 45.1730 \\
\hline 1979 & 120 & 12974 & 3.3098 & 10.6726 & 17.7729 & 7.4712 & 11.5233 \\
\hline 1980 & 50507 & 25995 & 14.9912 & 12.6976 & 55.7364 & 0.5017 & -5.2879 \\
\hline 1981 & 5533 & 19749 & 8.6247 & 11.8546 & 1.2082 & 2.4066 & -1.7052 \\
\hline 1982 & 1000 & 31622 & 5.6234 & 13.3351 & 3.6181 & 0.0050 & 0.1346 \\
\hline 1983 & 0 & 0 & 0.0000 & 0.0000 & 56.6338 & 179.7185 & 100.8868 \\
\hline
\end{tabular}




\begin{tabular}{|c|c|c|c|c|c|c|c|}
\hline Years & $x_{i}{ }^{\prime}$ & $y_{i}^{\prime}$ & $x_{i}$ & $y_{i}$ & $\left(x_{i}-\bar{x}\right)^{2}$ & $\left(y_{i}-\bar{y}\right)^{2}$ & $\left(x_{i}-\bar{x}\right)\left(y_{i}-\bar{y}\right)$ \\
\hline 1985 & 0 & 14906 & 0.0000 & 11.0494 & 56.6338 & 5.5530 & 17.7338 \\
\hline 1986 & 14933 & 23445 & 11.0545 & 12.3741 & 12.4535 & 1.0647 & -3.6413 \\
\hline 1987 & 28240 & 127521 & 12.9633 & 18.8971 & 29.5694 & 30.1532 & 29.8599 \\
\hline 1988 & 28972 & 59917 & 13.0465 & 15.6454 & 30.4811 & 5.0154 & 12.3643 \\
\hline 1989 & 16107 & 38388 & 11.2656 & 13.9974 & 13.9883 & 0.3499 & 2.2124 \\
\hline 1990 & 2667 & 156862 & 7.1861 & 19.9012 & 0.1152 & 42.1888 & -2.2048 \\
\hline 1991 & 65847 & 113772 & 16.0189 & 18.3658 & 72.1374 & 24.6000 & 42.1258 \\
\hline 1992 & 12053 & 57477 & 10.4780 & 15.4837 & 8.7167 & 4.3170 & 6.1343 \\
\hline 1993 & 980 & 65069 & 5.5951 & 15.9714 & 3.7267 & 6.5818 & -4.9526 \\
\hline 1994 & 0 & 62731 & 0.0000 & 15.8260 & 56.6338 & 5.8567 & -18.2123 \\
\hline 1995 & 23140 & 31844 & 12.3337 & 13.3585 & 23.1182 & 0.0023 & -0.2281 \\
\hline Total & 250177 & 889156 & 135.4598 & 241.3065 & $S_{x}=5.5303$ & $\mathrm{~S}_{y}=4.5566$ & $\mathrm{~S}_{x y}=13.3560$ \\
\hline Average & 13899 & 49398 & 7.5255 & 13.4059 & & & \\
\hline \multicolumn{8}{|c|}{ Years (Operation period) } \\
\hline 1996 & 20000 & 3804 & 15.8260 & 7.8534 & & & \\
\hline 1997 & 15000 & 17976 & 11.0668 & 11.5791 & & & \\
\hline 1998 & 140000 & 11121 & 19.3434 & 10.2692 & & & \\
\hline 1999 & 0 & 913 & 0.0000 & 5.4969 & & & \\
\hline 2000 & 694 & 0 & 5.1334 & 0.000 & & & \\
\hline 2001 & 0 & 28309 & 0.000 & 12.9712 & & & \\
\hline 2002 & 908 & 40096 & 5.4891 & 14.1506 & & & \\
\hline 2003 & 157 & 10642 & 3.5415 & 10.1568 & & & \\
\hline 2004 & 8432 & 8952 & 9.5827 & 9.7270 & & & \\
\hline 2005 & 9825 & 10950 & 9.9560 & 10.2295 & & & \\
\hline 2006 & 0 & 0 & 0.0000 & 0.0000 & & & \\
\hline 2007 & 1631 & 1336 & 6.3546 & 6.0458 & & & \\
\hline 2008 & 3000 & 27541 & 7.4008 & 12.8823 & & & \\
\hline 2009 & 70491 & 51750 & 9.1630 & 15.0826 & & & \\
\hline 2010 & 544181 & 21251 & 15.2734 & 12.0738 & & & \\
\hline 2011 & 334511 & 27866 & 13.5239 & 12.9202 & & & \\
\hline 2012 & 316951 & 47755 & 13.3429 & 14.7827 & & & \\
\hline 2013 & 38076 & 47116 & 13.9689 & 14.7330 & & & \\
\hline Total & 407069 & 357378 & 158.9662 & 180.9542 & & & \\
\hline Average & 22615 & 19854 & 8.8315 & 10.0530 & & & \\
\hline
\end{tabular}

\section{Results and Analysis}

\subsection{Determination of Target Area and Comparison Area}

According to the selection requirements of the target area and the comparison area: the target area affected by artificial catalysis should be located in the downwind direction of the working point; the contrast area not affected by artificial catalysis requires: first, it is in the upwind direction of the working area or perpendicular to the wind direction. The side is not affected by artificial catalysis; the second is that the topography, landform, area, etc. should be roughly equivalent to the working area; third, the correlation coefficient of the two-zone sample should be more than 0.05 [22].

The Kashgar region is located in the western part of the Akesu region, while the weather system in Xinjiang moves from west to east, so it is located in the upper reaches of the Akesu region in terms of the movement of the weather system. Both the Kashgar and Akesu regions are in the southern foothills of the Tianshan Mountains and the northern margin of the Tarim Basin. Therefore, the two regions meet the selection requirements of the comparison area and the target area respectively.

\subsection{Selection of Statistical Variables}

The selection of statistical variables is as follows: the target area and the comparison area should have corresponding data for more than 10 years before the operation period; secondly, the regional correlation between the target area and the comparison area should be better, and the natural variation of the statistical variable itself is smaller. The significance level of the sample correlation coefficient should be above 0.05 , and it is suitable for statistical tests. If the t-test is used, the statistical variables are required to have or be close to a normal distribution [22].

\subsubsection{Sample Condition}

Both the selected target area and the comparison area have 18 years of non-operational period data, which meets the non-operational period sample quantity requirement.

\subsubsection{Statistical Variable Distribution Condition}

The Kolmogorov distribution function and the fitness test were used to test the normal distribution of the historical disaster area in the two regions. Since the numerical value of the disaster relief area naturally varies greatly, in order to make the statistical variables closer to the normal distribution, the area of the disaster relief of the two areas is numerically transformed before the normal distribution test is performed. Through experimental analysis, the area of the disaster area in the target area and the comparison area was taken four times. After calculation, the fitting values of the historical values of the target area and the comparison area are 0.73 and 0.84 , 
respectively, which are both greater than the required 0.5 . Therefore, it is considered that the disaster area of the target area and the comparison area all meet the normal distribution of the fourth power root. According to the principle of mathematical statistics, it is possible to transform the annual disaster area of the two regions, establish a regression equation and perform statistical tests [23].

$$
\mathrm{r}=\frac{\sum_{i=1}^{n}\left(x_{i}-\bar{x}\right)\left(y_{i}-\bar{y}\right)}{\sqrt{\sum_{i=1}^{n}\left(x_{i}-\bar{x}\right)^{2} \sum_{i=1}^{n}\left(y_{i}-\bar{y}\right)^{2}}}=\frac{S_{x y}}{S_{X} S_{y}}
$$

$$
S_{x}=\sqrt{\frac{1}{n-1} \sum_{i=1}^{n}\left(x_{i}-\bar{x}\right)^{2}}, S_{y}=\sqrt{\frac{1}{n-1} \sum_{i=1}^{n}\left(y_{i}-\bar{y}\right)^{2}}, S_{x y}=\frac{1}{n-1} \sum_{i=1}^{n}\left(x_{i}-\bar{x}\right)\left(y_{i}-\bar{y}\right)
$$

$\mathrm{R}=0.53$ was calculated, $\mathrm{t}$ test is used to calculate $\mathrm{t}=\mathrm{r} \times$ $\sqrt{\frac{n-2}{1-r^{2}}}, \mathrm{t}=2.5$, unilateral test close to $\mathrm{t}_{0.01}=2.583$. Therefore, the significance level of correlation coefficient is close to 0.01 , much higher than the required 0.05 . Relevance meets the requirements.

Therefore, the choice of statistical variables meets the requirements.

\subsection{Regional Regression Analysis}

\subsubsection{Establish the Historical Regression Equation}

According to the principle of historical regression statistics, the linear fitting relation $y=a+b x$ between the four roots of hail disaster area in two regions was calculated by using the least square method, and the coefficient was calculated by the following formula:

\subsubsection{Sample Correlation and Significance Conditions}

The correlation and its significance were tested. For the area data of historic hail disaster that the fourth root of target area and contrast area obey normal distribution, the correlation coefficient $r$ of the statistical variables of the two areas is calculated by using the formula below:

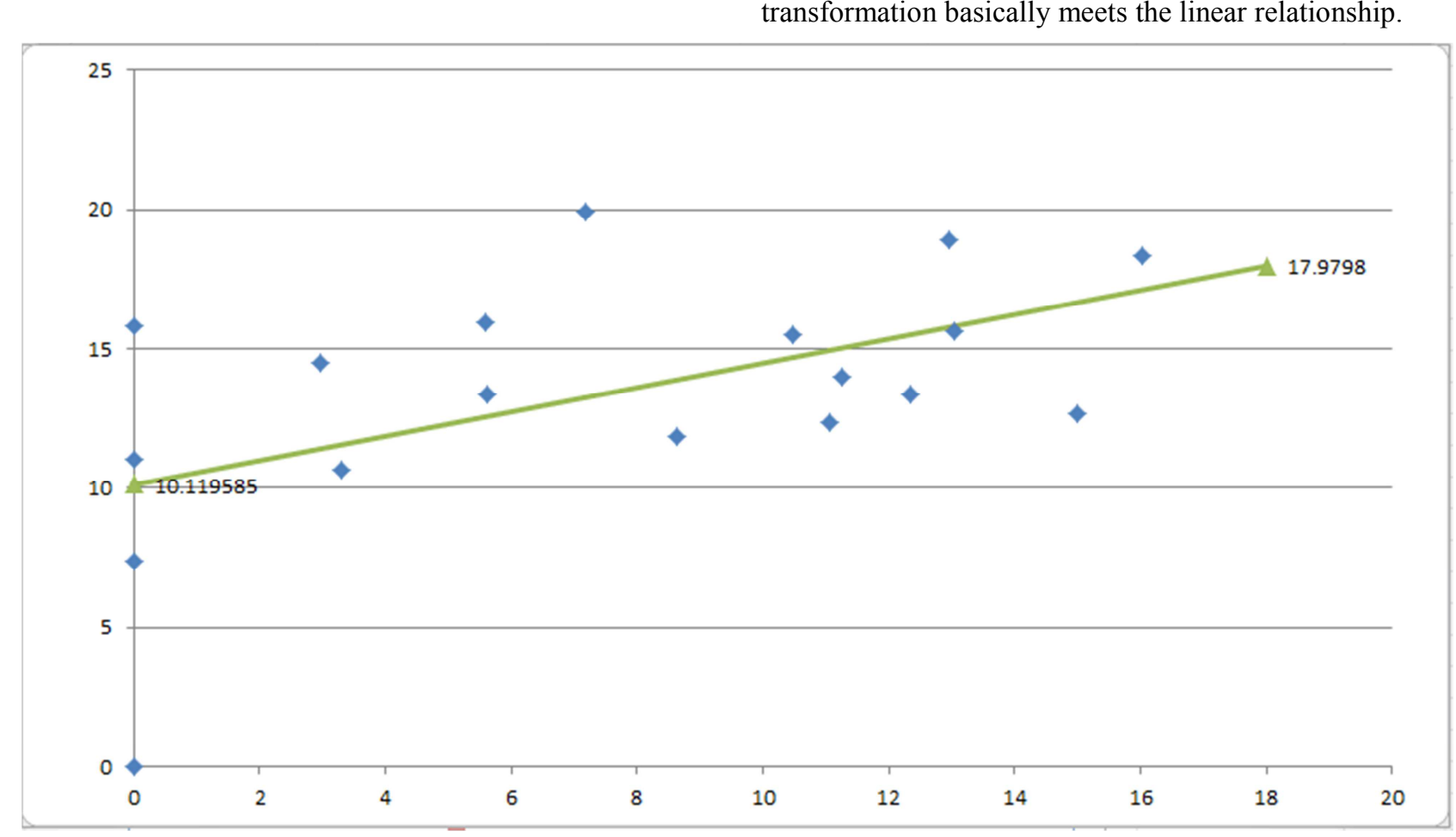

Figure 1. Linear regression results with the samples distribution. 


\subsubsection{Test for Significance of Linear Regression Equation}

The significance of regression equation was determined by using the f-test method of variance analysis under the condition that the four roots of the historic hailstorm area in the target area and the comparison area were generally normal distribution and the correlation between them was good [24]. $\mathrm{F}=\frac{Q_{\text {return }} / 1}{Q_{\text {remaining } /(n-2)}}$ obeys the F distribution with 1 degree of freedom and (n-2). The linear regression equation is significant when $\mathrm{F}>, \mathrm{F}$ end $(1, \mathrm{n}-2)$; the reverse is not significant. Among them: $Q_{\text {return }}=b^{2} \sum_{i=1}^{n}\left(x_{i}-\right.$ $\bar{x})^{2}, Q_{\text {remaining }}=\sum_{i=1}^{n}\left(y_{i}-\bar{y}\right)^{2}-Q_{\text {return }}$

By calculation, $\mathrm{F} \approx 6.25>\mathrm{F} 0.05=4.49$. Therefore, the linear regression equation is significant, with a confidence level of $96 \%$. This linear regression equation can be used to estimate the expected value of the fourth square root of the natural annual hail disaster area in the operating period.

\subsubsection{Effect Evaluation and Statistical Test}

By operation phase contrast area real annual hail area, by the four generations into the linear equation root transformation, can be calculated from the corresponding target zone in estimates of the hailstorm area of four root $\hat{y}_{k}$, by compared with areas of real annual hail area, it can evaluate the operational period the change of the target zone in hail area value: $\Delta \mathrm{y}=y_{k}-\hat{y}_{k}$. If delta $\mathrm{y}<0$, the artificial hail suppression operation is effective, and the effectiveness needs further test for significance.

To reduce the impact of natural variability, the t-test method of multiple events was used to quantitatively estimate the effect of artificial hail suppression operation [24].

$$
\mathrm{t}=\frac{\bar{d}_{k}}{\sqrt{\frac{1-r^{2}}{n-2} \sum_{i=1}^{n}\left(y_{i}-\bar{y}_{n}\right)^{2}\left[\frac{1}{k}+\frac{1}{n}+\frac{\left(\bar{x}_{k}-\bar{x}_{n}\right)^{2}}{\sum_{i=1}^{n}\left(x_{i}-\bar{x}_{n}\right)^{2}}\right]}}
$$

Among them: $\bar{d}_{k}=\frac{1}{k} \sum_{i=1}^{k}\left(y_{i}-\hat{y}_{i}\right)=\bar{y}_{k}-\overline{\hat{y}}_{k} ; \mathrm{n}$ and $\mathrm{r}$ are the correlation coefficients of the sample size and the correlation coefficients between the contrast region and the target region statistical variables when establishing the linear regression equation, respectively; $\bar{x}_{n}, \bar{y}_{n}$ contrast area and target zone respectively in the history of the hailstorm area of four root average; $\mathrm{k}$ is the sample size during the operation period; $\bar{x}_{k}, \bar{y}_{k}$ contrast area and target zone respectively in hail area of four root mean value of k times test; $\overline{\hat{y}}_{k}$ for target zone in hailstorm area of four root estimate average test $\mathrm{k}$ times.

Relevant data: $\bar{d}_{k}=-3.83, \mathrm{r}=0.53, \mathrm{n}=18, \mathrm{k}=18, \bar{x}_{n}=7.53$, $\bar{x}_{k}=8.61, \sum_{i=1}^{n}\left(x_{i}-\bar{x}_{n}\right)^{2}=519.94, \sum_{i=1}^{n}\left(y_{i}-\bar{y}_{n}\right)^{2}=352.96$ is substituted into the above formula to calculate $t \approx-2.858$, the subject freedom argument $v=n-2=16 \mathrm{t}$ distribution. According to the distribution table, $\mathrm{t}<-\mathrm{t}_{0.02}=-2.583$, indicating $\mathrm{a}$ significant reduction value of annual hailstorm area in the target area during the operation period, and unilateral significance level $<0.01$.

\subsubsection{Estimation of Reduction in Disaster Losses}

The measured annual average hailstorm area in the target area during operation period was $19854 \mathrm{hm}^{2}$, while the estimated annual average hailstorm area by linear regression equation was $43656 \mathrm{hm}^{2}$. Therefore, the absolute reduction value of the average annual hail disaster area is $23802 \mathrm{hm}^{2}$, and the relative reduction rate is $54.5 \%$. Unilateral significance level was higher than 0.01 .

According to the 18a year agricultural output value and annual cultivated land area in Akesu region, the output value per hectare can be estimated to be about 18,661 yuan. Therefore, the average annual loss of hail disaster was reduced by 444.17 million yuan, accounting for $5.51 \%$ of the annual average agricultural output value. After the scientific development of artificial hail prevention in Akesu region, the annual investment of artificial hail prevention is about 45 million yuan, so the average annual input and output ratio is $1: 10$.

\section{Discussion}

As the cloud and precipitation became too bad naturally, the spatial and temporal distribution of hail would change greatly, which made the area of hail disaster fluctuate greatly. The statistical test of the effect of artificial hail suppression is equivalent to extracting the "signal" of the effect of artificial hail suppression from these high "noises". Therefore, the efficacy of statistical test methods is often not high [22-23]. However, statistical test is one of the main methods to test the effectiveness of artificial hail suppression operation. From the perspective of statistics and artificial weather, compared with sequence test, non-pair rank sum test, t-test and Welch test, the regional regression test adopted in this paper has higher test efficacy and accuracy [22]. The so-called regression analysis is to find the statistical correlation of non-deterministic relations, and use it to estimate another variable of statistical correlation from one or more variables, and at the same time determine its accuracy. In the process of regression test analysis, first of all, the two variables should have a certain correlation $r$, which can be tested for significance by t test, otherwise the regression equation is meaningless [25]. Secondly, in order to analyze whether the variation of variables is mainly caused by independent variables or other factors, $F$ test method is used to test the significance of regression equation [23]. While using statistical test, we should also pay attention to using information such as the change of echo of weather radar to carry out physical test so as to show the dynamic effect of artificial hail suppression.

\section{Conclusion}

According to the conditions of regional regression analysis, the analysis requirements are met in terms of the determination of the contrast region-target region, the selection of statistical variables and the number of samples.

The sample correlation of linear regional regression equation was established by t test. The established linear regression equation is $96 \%$ credible by $\mathrm{F}$ test, with high significance. 
According to the regional regression analysis, the average annual hail disaster area in Akesu area decreased by 23802 $\mathrm{hm}^{2}$ after the scientific and artificial hail suppression operation, the relative reduction rate was $54.5 \%$, and the average annual hail disaster loss was reduced by 444.17 million yuan, accounting for $5.51 \%$ of the annual average agricultural output value, and the average annual input output ratio was $1: 10$. The statistical significance level was as high as 0.01 .

Compared with sequence test, non-pair rank sum test, t-test and Welch test, the regional regression test has higher test efficacy and accuracy. However, the sample similarity, sample quantity, quality and calculation process require higher.

\section{References}

[1] Rasul·ABLA, NIU Sheng-jie, Ablimitjan·ABLIKIM, et al. Study of the method of partitional hail forecast in Xinjiang region [J]. Journal of Glaciology and Geocryology, 2015, 37 (4): 1041-1049. (in Chinese)

[2] Resuli·ABULA, NIU Sheng-jie, WANG Hong-yan. Spatial temporal distribution characteristic of hail in Xinjiang [J]. Journal of Natural Disasters, 2013, 22 (2): 158-163. (in Chinese)

[3] ZHANG Jun-lan, ZHANG Li. Climate characteristics of severe hail events during 50 years in Aksu, Xinjiang, China [J]. Journal of Desert Research, 2011, 31 (1): 236-241. (in Chinese)

[4] SHI Lian-mei, ZHAO Zhi-peng, WANG Xu. Temporal and spatial distribution features of hail disaster in Xinjiang from 1961 to 2014 [J]. Journal of Glaciology and Geocryology, 2015, 37 (4): 898-904. (in Chinese)

[5] Mansur SABIT. Analyzing the spatio-temporal variations of hail disasters in southern Xinjiang region during recent 60 years [J]. Journal of Glaciology and Geocryology, 2012, 34 (4): 795-801. (in Chinese)

[6] CAI Yi-yong, WANG Hong, YU Yong-jiang. Spatiotemporal distribution and weather characteristics of hail in Fujian Province [J]. Journal of Natural Disasters, 2009, 18 (4): 43-48. (in Chinese)

[7] MA Xu-jie, CHEN Shu, REN Yu-long, et al. Analysis of climatic characteristic of hail and its short-time prediction system in Linxia of Gansu Province [J]. Journal of Arid Meteorology, 2012, 30 (2): 293-297. (in Chinese)

[8] WANG Xian-bin, ZHANG Dan-mei, Xin Yan-hui, et al. Study on potential forecasting and short-time nowcasting models of hailstone in Fuxin [J]. Chinese Journal of Agrometeorology, 2013, 34 (1): 106-113. (in Chinese)

[9] YIN Xue-lian, DONG An-xiang, DING Rong. Features and short-term forecast of hail in Zhangye City [J]. Plateau Meteorology, 2004, 23 (6): 804-809. (in Chinese)
[10] LI Yao-dong, GAO Shou-ting, LIU Jian-wen. A calculation of convective energy and the method of severe weather forecasting [J]. Journal of Applied Meteorological Science, 2004, 15 (1): 10-20. (in Chinese)

[11] LIU Yu-ling. A study of severe convective parameters and their potential predictability to severe convective storms [J]. Meteorological Science and Technology, 2003, 31 (3): 147-151. (in Chinese)

[12] HONG Yan-chao. Study on mechanism of hail formation and hail suppression with seeding [J]. Acta Meteorologica Sinica, 1999, 57 (1): 30-44. (in Chinese)

[13] XU Huan-bin, DUAN Ying. The mechanism of hailstones formation and the hail suppression hypothesis beneficial competition [J]. Chinese Journal of Atmospheric Sciences, 2001, 25 (2): 277-288. (in Chinese)

[14] WANG Bai-zhong, WANG Guang-he, GAO Bin-yong. Effect of hail suppression on agricultural disaster [J]. Journal of Natural Disasters, 2009, 18 (2): 27-32. (in Chinese)

[15] Wang Qiu-xiang, RenYi-yong. Temporal and spatial distribution features of hail disasters in Xinjiang in recent 51 years [J]. Arid Land Geography 2006, 29 (1): 65-69

[16] Chen Hong-wu, $\mathrm{Ma} \mathrm{Yu}$, Wang $\mathrm{Xu}$, et al. Climatic characteristics of hail weather in Xinjiang [J]. Meteorology, 2003, 29 (11): 25-28

[17] Wang Xu, MA Yu. Basic characteristics of hail weather in Xinjiang [J]. Xinjiang Meteorology, 2002, 25 (1): 10-14.

[18] Ma Yu, Wang Xu, Zhao Bing-ke, et al. Spatial and temporal statistical character of hail in Xinjiang [J]. Xinjiang Meteorology, 2002, 25 (1): 4-5.

[19] Yang Lian-mei. Climatic characteristics of hail in Xinjiang and prevention [J]. Disaster, 2002, 17 (4): 26-31.

[20] LI Li-hua, CHEN Hong-wu, MAO Wei-yi, et al. GIS-based hail risk zonation and assessment in Aksu Prefecture [J]. Arid Zone Research, 2010, 27 (2): 221-229.

[21] LI Bin, ZHENG Bo-hua, SHI Lian-mei, et al. Statistical evaluation of hail suppression effect in Akesu, Xinjiang [J]. Xinjiang Agriculture Sciences, 2016, 53 (5): 942-948.

[22] CHEN Guang-xue, DUAN Ying, WU Dui, et al. Rocket Weather Modification Technology [M]. Beijing: Meteorological Press, 2008: 193, 198-199, 317-318. (in Chinese)

[23] YE Jia-dong, FAN Pei-fen. Statistical Mathematical Methods of Weather Modification [M]. Beijing: Science Press, 1982: 196-202, 301. (in Chinese)

[24] Deng Bei-sheng. Weather Modification Technology and Management [M]. Beijing: China Meteorological Press, 2011: 146-147.

[25] Science and Technology Education Department of China Meteorological Administration. On-the-job Training Materials of Weather Modification [M]. Beijing: Meteorological Press, 2003: 146-1. 